\title{
Towards a Theory of Rewriting: Drawing from the Indian Practice
}

K.M. Sherrif

\begin{abstract}
The present paper draws attention to the domain of rewriting which constitutes an important segment of translational practices in popular culture. The aesthetic and ideological implications of such rewritings have not received much attention in Culture Studies. Among popular forms of rewritings are dramatizations of novels, cinematizations of literary works and renderings of literary works in performing art forms like kathakali and opera. The paper argues that the rewritings of literary texts in the performing arts of kathaprasangam and harikatha in Malayalam and other languages need to be studied in the context of Culture Studies and Translation Studies.
\end{abstract}

Andre Lefevere was the first Translation Studies scholar to position translation in a paradigm of rewriting (Lefevere 1984, 1987). The notion that translation can only be a rewriting of the source text was by this time an accepted fact in Translation Studies. Lefevere, however, pointed out that translation was only one of the many forms of rewriting, and that the role of translations in any culture could only be understood in relation to the role of the other forms of rewriting in that culture. The forms of rewriting Lefevere enumerated included criticism (which he considered the most important form of rewriting after translation), the review, the blurb, trans-genre rewritings like the dramatization of a novel and intersemiotic rewritings like the cinematic version of a literary text. Lefevere's ideas on the nature of rewriting and the diverse ways in

Translation Today Vol. 3 Nos. 1 \& 2, 2006 C CIIL 2006 
which rewritings position themselves in the matrix of a culture were not significantly developed by literary theorists, including Translation Studies scholars, who came after him. This paper makes an attempt to briefly inquire into the ways in which a theory of rewriting can be developed, how it can draw substantially from the traditional and modern practice of rewriting in India, and how such a theory can make substantial contributions to Culture Studies.

The crisis in Translation Studies as a discipline has become quite apparent today. There are a number of reasons for this crisis. The first is that of nomenclature. Translation Studies has made forays across its frontiers in the last quarter of the century after its emergence as a full-fledged discipline in 1983. ${ }^{1}$ Border-crossings have been quite frequent, and quite successful too in tackling other forms of rewriting. Dubbing and subtitling in cinema were the "near abroad'; Dirk Delabastita (1990) discusses the nature of translation (rewriting) in the mass media, outlining the complexities in rewriting texts in cinema and on radio and television. Cinematic versions of literary texts and intra-lingual and extra-lingual remakes of films apart, Delabastita shows how dubbing and sub-titling have to contend with complexities of both the target culture and the medium. The possibilities of border-crossings were fully demonstrated in the National Translation Seminar held at IIT, Mumbai in December 2004. The topics discussed included 'rewriting' of theme music by dramatic troupes crossing cultural boundaries, the notion of translation in music, translation of visual poetry and the remaking of films.

Secondly, Translation Studies has virtually exhausted its theoretical resources. The eighties and nineties of the last century saw a veritable explosion in translation theory as Translation Studies scholars, generously assisted by literary theorists in other areas, broke new ground in the discipline and effectively positioned it within the domain of Culture Studies. In fact the Rewriting-Culture paradigm in Translation Studies is one of the most revolutionary 
advances in both literary theory and Culture Studies in the twentieth century. Translation Studies went on to make seminal contributions to every theoretical paradigm or critical approach which came to be considered revolutionary or avant-garde: deconstruction, postcolonial studies, feminist studies, subaltern studies, even queer theory. ${ }^{2}$ Translation theory has effectively offered tools for interrogating asymmetrical relations between hegemonic and marginalized cultures, patriarchal structures embedded in discourses, the marginalization of subaltern cultures within cultures which are themselves marginalized globally, the appropriation of cultural resistance in translation and the operation of market fundamentalism in translation, to mention only the more obvious areas. In fact, Translations Studies scholars like Lefevere, Bassnett, Hermans, and Venuti even called for the demolition of the Euro-centrism of the discipline in the West. Sujit Mukherjee, Harish Trivedi and Ayyappa Panikker in India offered theoretical paradigms which challenged the Western notions on translation. No wonder translation theory looks so exhausted today and descriptive Translation Studies are proliferating.

The vast unchartered terrain of cultural rewriting offers challenges for Translation Studies scholars to widen their horizons, and in the process bring the discipline closer to Culture Studies. The Indian tradition of rewriting is quite remarkable. Literary rewriting has, of course, occupied the attention of Translation Studies scholars and literary theorists alike. It needs hardly be stated that, unlike in the West, where faithfulness in translation was an inviolable ideal till quite recently, literary texts were not translated, but merely rendered in a new form, i.e. rewritten in India. That such rewriting, starting with the epics Ramayana and Mahabharata in the various spoken languages of India, had both aesthetic and socio-political implications, especially in contexts like the Bhakti movement, is widely recognized today. But the tradition of inter-semiotic rewriting, as in the rewriting of literary texts in performing arts, has 
hardly come to the notice of Translation Studies scholars. The aesthetic and socio-political distance that separates the rewriting of Ramayana by poets like Ezhuthachan or Tulsidas who can be positioned within the Bhakti movement and the rewriting of the same text, or portions of it, in performing arts like Kathakali or Yakshagana is worthy of intensive study. The stark contrast between the devotional fervour of Ezhuthachan's verses and the stylized mudras of Kathakali with their alienating effect, stares one in the face. The topical allusions the Chakyar performing a Koothu (a performing art form in Kerala which is desperately struggling for survival) insinuates into his mixed verse-prose rendering of contexts from Ramayana and Mahabharata and his frequent implication of the audience in the narrative deserves attention from scholars. The strains of Chinese music woven into a Manipuri dance performance, many of whose themes are derived from the great Indian epics, also ought to interest the Translation Studies scholar.

There have been more fascinating instances of rewriting in India in recent times. One of them is Kathaprasangam, a secular form of Harikatha, whose popularity once rivaled that of cinema in Kerala. Kathaprasangam evolved in the state in the early decades of the twentieth century and Joseph Kaimapparamban is generally regarded as having pioneered the form. Perhaps the greatest exponent of the form was Kedamangalam Sadanandan, a cardholding communist, whose performances, along with the plays staged by the KPAC, served as the cultural bulwark for the communist movement in the state. Sadanandan chose most of his themes from contemporary Malayalam literary texts, especially those which reflected the turbulent transformation Kerala society was undergoing in the mid-twentiety century. Sadanandan had a remarkable successor in Sambasivan, who apart from using Malayalam literary texts, adapted texts which are still regarded as the classics of the 'world literature'. Sambasivan's Othello and Anna Karenina became quite popular. There is, of course, a school of opinion which accuses Sambasivan of trivializing classics, of 
literally dragging them to the marketplace. What one tends to forget is that most non-professional readers in any culture have had access to a large body of the 'world literature', including the classics, only through rewritings: retellings of stories, reviews, critical articles, encyclopedias and other books for reference. An important phase in the history of Kathaprasangam in Kerala is the emergence of a number of Muslim women artists like Zeena Pallikkara, Ramla Begum and Ayesha Begum during the sixties and of the last century. Apart from stories from the Khur-aan and Malayalee Muslim folklore, they adapted texts which recorded themes from the ferment of social transformation in their community. In fact the history of the Left-led Progressive Literary Movement in Kerala will be incomplete without reference to Sadanandan, Sambasivan and the Muslim women artists.

Popular culture provides more instances of both the rigid enforcement of inter-cultural embargoes on rewriting and on their effortless lifting. Dubbing and remaking of films across languages have been a common phenomenon in Indian cinema from its early years. The location of the film industry in the metropolises of Mumbai, Chennai and Calcutta facilitated dubbing and remaking, especially when Hindi was either the target language or the source language. Till the early eighties Hindi was, more often than not, the source language. Powerful storylines and technical perfection in Malayalam and Tamil cinema reversed the trend. The popularity of composers like A.R. Rahman also ensured that the songs in the films were 'translated' in the remakes. Given the cultural matrices from which popular cinema operates, certain contexts have to be drastically rewritten. Two instances may be cited to illustrate the point. In the Malayalam film Ramjirao Speaking, which was a great commercial success, the typical 'Mappila' (Malayalee Muslim) humour is tapped to devastating effect. Majeed (played by Mamukoya) the bosom-friend of the protagonist and his cronies provide explosive humour towards the end of the film. In the Hindi 
remake, the bosom-friend (played by Om Puri) and his cronies are Sikhs. In the popular imagination, humour is not a strong point of the North Indian Muslim, while it is of the Punjabi Sardar. In Godfather, another commercially successful Malayalam cinema, the patriarch Anjooran (played by the playwright and actor N.N. Pillai) cannot help looking ludicrously funny in a number of scenes, given the history of the anti-feudal struggles in Kerala in the twentieth century. In Hulchul, the Hindi remake, Anjooran's counterpart (played by Amrish Puri), who does not have the burden of history on his back, looks every bit the terrifying Thakur.

The translation of film songs in remakes provokes a rethinking of traditional notions of faithfulness in translation. The lyrics in the remakes are often linked to the lyrics in the original film only by the identical tune in which they are sung. In semantic content, only the mood is retained to fit into an identical or similar context: a romantic rendezvous, a boisterous gathering of young people or the solitary reverie of the love-torn boy or girl. Without the tune, very little remains to link the songs in an inter-textual relationship. As the notion of poetry being lost in translation goes up in smoke, popular culture has the last laugh.

A theoretical framework that can engage all forms of cultural rewriting can be developed out of the basic principles of translation theory formulated in the last quarter of the twentieth century. The varied forms of cultural rewriting in India points to such a development. Although it is too early to see Translation Studies evolving into a fully blown branch of Culture Studies called Rewriting Studies which can account for the rewriting of all cultural phenomena, it is clear that the discipline can, ultimately, have no other destiny. 


\section{NOTES}

1. Translation Studies which used to be included under headings of either 'Linguistics' or 'Comparative Literature' was given a separate bibliographical entry by the Modern Language Association of America in 1983.

2. See Keith Harvey "Translating Camp Talk: Gay Identities and Cultural Transfer" Lawrence Venuti (ed.) Translation Studies Reader, London: Routledge, 2000.

\section{REFERENCES}

Delabastita, Dirk 1990 "Translation and the Mass Media" in Andre Lefevere \& Susan Bassnett (ed) Translation, History, Culture London: Routledge.

Lefevere, Andre 1985 "Why Waste Our Time on Rewrites?: The Trouble with Interpretation and the Role of Rewriting in an Alternative Paradigm." In Theo Hermans (ed) The Manipulation of Literature: Studies in Literary Translation. New York: St. Martins Press.

1987 “'Beyond Interpretation' or the Business of (Re) Writing Comparative Literature Studies 24: 1 (17-39). Papyrus.

1988 Essays in Comparative Literature Calcutta:

1992 Translation and the Manipulation of Literary Fame London: Routledge. 
